PEREIRA, F.H.F.; NOGUEIRA, I.C.C.; PEDROSA, J.F.; NEGREIROS, M.Z.; BEZERRA NETO, F. Poda da haste principal e densidade de cultivo sobre a produção e qualidade de frutos em híbridos de melão. Horticultura Brasileira, Brasília, v. 21, n. 2, p. 191-196, abril/junho 2003.

\title{
Poda da haste principal e densidade de cultivo na produção e qualidade de frutos em híbridos de melão
}

\author{
Francisco Hevilásio F. Pereira ${ }^{1}$; Isení C.C. Nogueira² ${ }^{2}$ Josué F. Pedrosa ${ }^{2}$; Maria Z. Negreiros²; Francisco \\ Bezerra Neto ${ }^{2}$
}

${ }^{1}$ UFV, Depto. Fitotecnia, 36571-000, Viçosa-MG. E.mail: fhfpereira@hotmail.com; 2ESAM, Depto. Fitotecnia, C. postal 137, 59625-900, Mossoró-RN.

\section{RESUMO}

Avaliou-se os efeitos da poda da haste principal e da densidade de cultivo sobre a produção e a qualidade de dois híbridos de melão. Os trabalhos foram desenvolvidos na ESAM em Mossoró-RN, de 01/06 a 11/08/98. Foram desenvolvidos dois experimentos, sendo um com e o outro sem poda da haste principal. Em cada um estudaram-se os híbridos Orange Flesh e Hy Mark e as densidades de cultivo de 20.000, 30.000, 40.000 e 50.000 plantas ha $^{-1}$, arranjados em esquema fatorial $2 \times 4$. O delineamento experimental utilizado foi blocos casualizados com quatro repetições. Houve interação significativa entre a poda da haste principal e os híbridos para massa média dos frutos, relação de formato e sólidos solúveis totais e entre a poda da haste principal e a densidade de cultivo para o número de frutos totais e não-comercializáveis. Os híbridos Orange Flesh e Hy Mark, quando submetidos à poda, foram mais produtivos apresentando, em média, 25,96 $\mathrm{Mg} \mathrm{ha}^{-1}$ de frutos comercializáveis. A produtividade e a massa média dos frutos diminuíram com o aumento da densidade de cultivo. O número de frutos totais e comercializáveis aumentaram em função da densidade de cultivo. O híbrido Orange Flesh, submetido à poda, apresentou a maior relação de formato, com índice de 1,09, enquanto o híbrido Hy Mark apresentou a menor, com índice de 1,04. O híbrido Hy Mark submetido à poda da haste principal apresentou o maior teor de sólidos solúveis totais $(8,99 \%)$.

Palavras-chave: Cucumis melo, poda, população de plantas, sólidos solúveis.

\begin{abstract}
Pruning of main stem and plant density on yield and fruit quality of melon hybrids

Two field trials were carried out to evaluate the effect of pruning and planting density on yield and fruit quality of two melon hybrids. The work was done in Mossoró, Brazil, in the period of 06/01 to 08/ 11/98. The hybrids Orange flesh and Hy Mark were studied and the planting densities of 20,000; 30,000; 40,000 and 50,000 plants ha ${ }^{-1}$, in factorial outline $2 \times 4$. The experimental design was of randomized blocks, with four replications. There was significant interaction among pruning and hybrid for medium weight of fruits, format relationship and total soluble solids and between pruning and planting density for the total number of fruits and number of unmarketable fruits. The hybrid submitted to the pruning provided larger productivity, with the hybrid Orange Flesh and Hy Mark presenting 25.96 Mag ha-1 on average. The yield and the medium weight of fruits decreased with the increase of the planting density. The total number of marketable fruits increased in function of the planting density. The hybrid Orange Flesh submitted to pruning presented the largest format relationship with index of 1.09 , while the hybrid Hy Mark presented the smallest with index of 1.04. The hybrid Hy Mark submitted to pruning presented the largest level of total soluble solids $(8,99 \%)$.
\end{abstract}

Keywords: Cucumis melo, pruning, plant population, soluble solids.

(Recebido para publicação em 14 de março de 2002 e aceito em 9 de abril de 2003)

$\mathrm{O}$ melão é cultivado em 72 países, tendo ocupado em 1999, área de 1,13 milhões de ha, com produção de 19,51 milhões de toneladas e rendimento médio de 18 t/ha (Pimentel et al., 2000). O Brasil é o terceiro maior produtor de melão da América Latina, sendo a Região Nordeste responsável por 90\% da produção nacional, destacandose os estados do Rio Grande do Norte e Ceará com $67 \%$ do volume produzido no País (Dias et al., 1998).

No Nordeste brasileiro, há condições edafo-climáticas favoráveis para o cultivo do melão, dentre elas, precipitações pluviais que ocorrem apenas durante três meses do ano. Assim é possível colher até três safras/ano, com as cultivares disponíveis dos grupos Cantaloupensis, Inodorus e Momordica apresentando períodos de maturação do fruto de 31,5 ; 30,6 e 24,4 dias após o início da frutificação, respectivamente (Paiva et al., 2000).

A intensificação dos métodos de produção, incluindo o uso de plástico em cobertura do solo, irrigação por gotejamento, fumigação e, em alguns casos, fertirrigações, pode favorecer as densidades de semeio maiores do que as tradicionalmente usadas (Maynard, 1998). As interações estabelecidas entre planta, ambiente e práticas fitotécnicas utilizadas condicionam respostas fisiológicas e, conseqüentemente, agronômicas, não só do ponto de vista quantitativo (rendimento), como também qualitativo (características organolépticas e nutricionais) e distribuição espacial da colheita ao longo do tempo. Essas associações são bastante evidenciadas no meloeiro, sendo que sua eficiência será maior à medida que as condições ambientais (clima e solo) sejam adequadas e possam ser favorecidas por práticas de manejo tais como densidade de cultivo, cobertura do solo, métodos de condução de plantas, poda, desbaste e raleio (Martins et al., 1998).

A poda vem sendo utilizada em algumas hortaliças, com o objetivo de aumentar a produção e melhorar a qualidade dos frutos, além de facilitar outras práticas culturais. Em melão, a poda 
da haste principal promove o rápido crescimento das hastes laterais, em razão da ação de auxinas e outros fitohormônios que causam a translocação de fotoassimilados para as gemas secundárias. Na cv. Valenciano Amarelo, a poda induziu alteração no formato dos frutos, sendo que aqueles provenientes de plantas podadas apresentaram frutos de formato ligeiramente mais alongado (Pedrosa et al., 1991). Monteiro \& Mexia (1988) verificaram que as plantas de melão podadas após a segunda folha apresentaram maior área foliar e altas correlações entre a área foliar por fruto e o seu teor de sólidos solúveis e entre a área foliar por fruto e a sua massa média. Concluíram que quanto maior a área foliar à disposição de cada fruto tanto maiores serão sua massa média e o teor de sólidos solúveis dos frutos.

Atualmente, os produtores de melão usam populações que variam de 10 a 30 mil plantas ha $^{-1}$, dependendo da finalidade da comercialização, considerandose que maiores populações permitem a obtenção de frutos menores, preferidos para exportação (Pedrosa, 1997). Alguns cultivares não se adaptam à maior densidade de plantio e podem emitir frutos deformados, aumentando a produção de frutos não-comercializáveis. Dusi (1992) destaca que o espaçamento para melão a ser adotado é função do nível de fertilidade do solo, sendo que para os de alta fertilidade usa-se o espaçamento de $2,0 \times 1,0 \mathrm{~m}$ ou $2,0 \mathrm{x}$ $0,50 \mathrm{~m}$, salientando, contudo, que no Vale do São Francisco adota-se espaçamento de $1,5 \times$ x 0,25 m com uma planta por cova, o que representa população de, aproximadamente, 26.600 plantas ha-1.

Os tipos de melão cultivados, atualmente, são predominantemente de cultivares e, ou híbridos do tipo amarelo, no entanto, novos tipos como Cantaloupe e Honey Dew estão sendo introduzidos (Pedrosa, 1997). Necessita-se, portanto, de pesquisas sobre novas técnicas de manejo, procurando proporcionar aos produtores subsídios para os sistemas de produção.

Objetivou-se, neste trabalho, avaliar os efeitos da poda e densidade de cultivo na produção e qualidade de frutos dos híbridos de melão Orange Flesh e Hy Mark, cultivados em Mossoró.

\section{MATERIAL E MÉTODOS}

O trabalho foi desenvolvido na ESAM, em Mossoró, de 01/06 a 11/08/ 98, em solo classificado como Luvissolo Crônico (Alfissol). Os resultados das análises químicas de amostras do solo foram: $\mathrm{pH}$ em água $(1: 2,5)=7,9 ; \mathrm{P}(\mathrm{mg}$ $\left.\mathrm{kg}^{-1}\right)=388 ; \mathrm{K}\left(\mathrm{cmol}_{\mathrm{c}} \mathrm{kg}^{-1}\right)=0,64 ; \mathrm{Ca}$ $\left(\mathrm{cmol}_{\mathrm{c}} \cdot \mathrm{kg}^{-1}\right)=6,8 ; \mathrm{Mg}\left(\mathrm{cmol} \mathrm{kg}_{\mathrm{c}}^{-1}\right)=3,2$; $\mathrm{Na}\left(\mathrm{cmol}_{\mathrm{c}} \mathrm{kg}^{-1}\right)=0,84 ;$ Al trocável $\left(\mathrm{cmol}_{\mathrm{c}} \mathrm{kg}^{-1}\right)=0,00$.

Foram desenvolvidos dois experimentos, um com e outro sem poda da haste principal. Em cada um deles foram estudados dois híbridos de melão (Orange Flesh e Hy Mark) e quatro densidades de cultivo (duas, três, quatro ou cinco plantas por gotejador, no espaçamento $2,0 \times 0,5 \mathrm{~m}$, correspondendo, respectivamente, a $20.000,30.000,40.000$ e 50.000 plantas ha-1). Os tratamentos foram arranjados em esquema fatorial $2 \times 4$, no delineamento experimental de blocos casualizados, com quatro repetições.

O preparo do solo constou de uma gradagem e sulcamento com aproximadamente $20 \mathrm{~cm}$ de profundidade, onde foi realizada a adubação de plantio, com base nas análises do solo. Utilizaramse $20 \mathrm{t} \mathrm{ha}^{-1}$ de esterco bovino, $120 \mathrm{~kg}$ ha $^{-1}$ de N, $297 \mathrm{~kg} \mathrm{ha}^{-1}$ de $\mathrm{K}_{2} \mathrm{O}$ e $95 \mathrm{~kg} \mathrm{ha}$ ${ }^{1} \mathrm{de} \mathrm{P}_{2} \mathrm{O}_{5}$, usando-se como fontes sulfato de amônio, cloreto de potássio e superfosfato triplo, respectivamente. As adubações de cobertura foram efetuadas em fertirrigação, diariamente, de acordo com os estádios de desenvolvimento da cultura. As quantidades totais utilizadas durante o ciclo da cultura foram $495 \mathrm{~kg} \mathrm{ha}^{-1}$ de cloreto de potássio, 118 $\mathrm{kg} \mathrm{ha}^{-1}$ de uréia, $479 \mathrm{~kg} \mathrm{ha}^{-1}$ de nitrato de cálcio e $182 \mathrm{~kg} \mathrm{ha}^{-1}$ de ácido fosfórico. As capinas, irrigações e controle fitossanitário foram realizados de acordo com as necessidades da cultura.

A semeadura foi realizada diretamente nas covas, e posteriormente fezse o desbaste deixando-se duas, três, quatro ou cinco plantas por gotejador. A parcela tinha $5 \mathrm{~m}$ de comprimento, com três fileiras de plantas, espaçadas de $2 \mathrm{~m}$, totalizando área de $30 \mathrm{~m}^{2}$. Con- siderou-se como parcela útil a fileira central, excluindo-se as plantas das extremidades. A poda da haste principal foi efetuada quando as plantas apresentavam de quatro a cinco folhas definitivas, eliminando-se a gema apical, deixando-se apenas três folhas.

Foram realizadas três colheitas dos frutos, aos 64, 68 e 70 dias após o semeio, quando avaliou-se produtividade de frutos comercializáveis, número total de frutos, número de frutos comercializáveis e nãocomercializáveis, número de frutos comercializáveis por planta, massa média dos frutos comercializáveis, relação de formato (diâmetro longitudinal dividido pelo diâmetro transversal) e sólidos solúveis totais de frutos comercializáveis. Foram considerados comercializáveis os frutos que apresentavam os atributos mínimos de qualidade e massa exigida pelo mercado (Filgueiras et al., 2000). Quanto à relação de formato (RF), consideraram-se frutos esféricos, oblongos e cilíndricos, aqueles com relação de formato menor que 1,0; entre 1,1 a 1,7 e maior que 1,7, respectivamente, conforme Lopes (1982).

As análises de variância conjunta das características avaliadas foram realizadas utilizando-se o programa computacional SAEG (Ribeiro Júnior, 2001). Para os fatores quantitativos foi feita análise de regressão utilizando-se o software Table curve (Jandel Scientific, 1991), enquanto para os fatores qualitativos, no desdobramento das interações, foi utilizado o teste de Tukey, até $5 \%$ de probabilidade.

\section{RESULTADOS E DISCUSSÃO}

Não houve interação significativa entre os fatores estudados para produtividade, número de frutos comercializáveis e número de frutos comercializáveis por planta.

A maior produtividade de frutos comercializáveis nas plantas podadas $\left(25.958 \mathrm{~kg} \mathrm{ha}^{-1}\right)$ em relação às plantas não podadas $\left(16.475 \mathrm{~kg} \mathrm{ha}^{-1}\right)$ pode ser atribuída à maior massa média e número de frutos nessas plantas. Pedrosa et al. (1991) não encontraram efeitos significativos da poda e densidade de se- 
meio em melão cv. Valenciano Amarelo sobre a produção. No entanto, obtiveram em plantas podadas e sem poda, produtividades de 16,5 e 15,0 $\mathrm{t} \mathrm{ha}^{-1}$, respectivamente, sendo portanto, menores que as encontradas neste trabalho. Carneiro Filho (2001) também não verificou efeito significativo da poda na produtividade do híbrido de melão cantaloupe D. Carlos.

O decréscimo em produtividade com o aumento da densidade de semeio (Figura 1A) pode ser atribuído principalmente às pressões de competição inter e intraplantas. Isso ocasionou menor disponibilidade de fotoassimilados por planta, proporcionando menor massa média e número de frutos por planta e, conseqüentemente, menor produtividade de frutos comercializáveis. Resultados semelhantes foram obtidos por Mendlinger (1994), em melão tipo Gália (20, 40 e 80 mil plantas ha $\left.^{-1}\right)$ e Chaves et al. (2001b), em Honey Dew e Cantaloupe (20, 30, 40 e 50 mil plantas $\left.\mathrm{ha}^{-1}\right)$. Nesses trabalhos, a densidade de 20.000 plantas ha $^{-1}$ foi a que proporcionou maior produtividade. Grangeiro et al. (1999a), em híbridos de melão Amarelo, sob populações de 20 a 40 mil plantas ha $^{-1}$, obtiveram máxima produtividade com 32.584 plantas ha-1.

Houve interação significativa entre a poda e a densidade de cultivo, ocorrendo aumento crescente do número de frutos total à medida que se aumentou $\mathrm{o}$ número de plantas ha ${ }^{-1}$, independentemente da poda (Figuras 1B). Mendlinger (1994) observou 24,43\% de aumento no número total de frutos de melão entre as populações de 10 a 40 mil plantas ha ${ }^{1}$. Grangeiro et al. (1999a) observaram aumento no número de frutos por hectare de 28,57\% (11.746 frutos ha $^{-1}$ ) com o aumento da densidade de 10 a 40 mil plantas ha-1. Maynard (1998) obteve resultados semelhantes na cultivar 'Superstar', mas não Bracy e Parish (1994), em melão 'Cantaloupe'.

O híbrido Hy Mark produziu mais frutos totais (30.438) e comercializáveis (18.937) que o Orange Flesh (27.813 e 17.375), respectivamente. Essa diferença pode ser atribuída à natureza genética inerente a cada híbrido, conferindo comportamentos distintos de acordo com o maior ou menor grau de adapta-

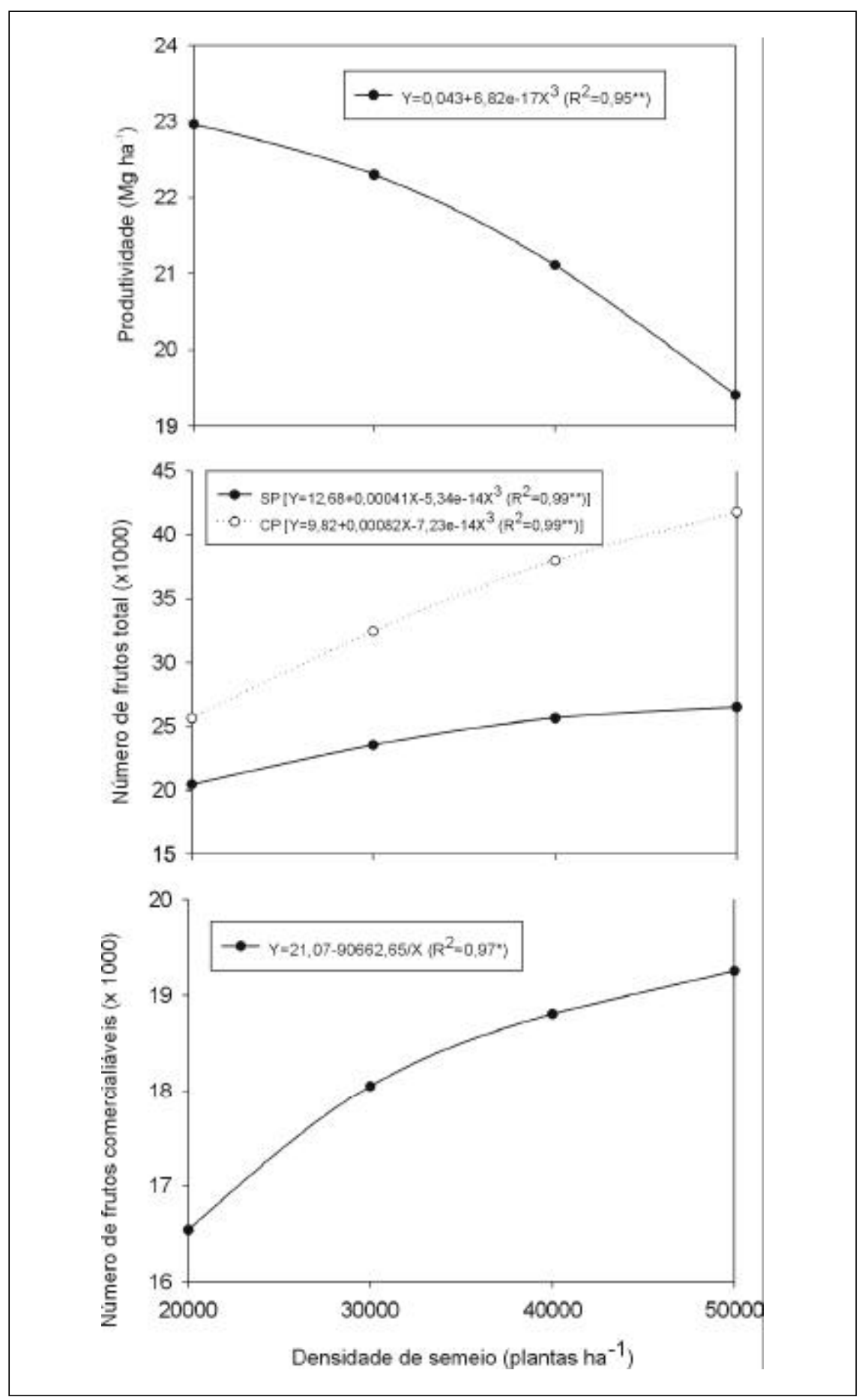

Figura 1. Produtividade (A), número de frutos totais (B) sem (SP) e com poda $(\mathrm{CP})$ e comercializáveis $(\mathrm{C})$ por ha ${ }^{-1}$ de melão em função das densidades de semeio. Mossoró-RN, ESAM, 1998.

ção dos materiais ao meio em que são cultivados. Diferenças também foram verificadas por Nogueira et al. (2001), confirmando desempenho superior do híbrido 'Hy Mark' em relação ao 'Orange Flesh'.

À medida que se aumentou a densidade de semeio, houve aumento no nú- mero de frutos comercializáveis (Figura $1 \mathrm{C}$ ), o que pode ser atribuído ao incremento no número de plantas por área, que mesmo produzindo frutos com massas médias menores, eles se encontravam dentro do intervalo de classificação comercial. Resultados semelhantes foram obtidos por Chaves et al. (2001b), 
Tabela 1. Massa média (kg), relação de formato e sólidos solúveis (\%) dos frutos dos híbridos de melão Orange Flesh e Hy Mark, com e sem poda. ESAM, Mossoró-RN, 1998.

\begin{tabular}{|c|c|c|}
\hline \multirow{2}{*}{ Variáveis } & \multicolumn{2}{|c|}{ Híbridos } \\
\hline & Orange Flesh & Hy Mark \\
\hline \multicolumn{3}{|l|}{ Massa média } \\
\hline Sem poda & $0,66 b^{1 /}$ & $0,74 \mathrm{~b} \mathrm{~A}$ \\
\hline Com poda & 1,29 a $A$ & 1,11 a $B$ \\
\hline \multicolumn{3}{|l|}{ Relação de formato } \\
\hline Sem poda & 1,07 a $A$ & 1,08 a $A$ \\
\hline Com poda & 1,09 a $A$ & 1,04 a B \\
\hline \multicolumn{3}{|l|}{ Sólidos solúveis } \\
\hline Sem poda & 7,83 a $A$ & $7,68 \mathrm{~b} \mathrm{~A}$ \\
\hline Com poda & 7,29 a $B$ & 8,99 a $A$ \\
\hline
\end{tabular}

nas mesmas densidades de semeio e híbridos, porém em ambiente diferente. No entanto, Pedrosa et al. (1991), na cv. Valenciano Amarelo verificaram comportamento inverso, tendo obtido com população de 10.000 plantas ha $^{-1} 87 \%$ mais frutos comercializáveis quando comparado a 20.000 plantas $\mathrm{ha}^{-1}$. Os autores afirmam que a menor competição resultou em número mais expressivo de frutos com maior massa média e menor número de frutos com defeitos. Essa divergência nos resultados pode ser explicada devido às características comerciais inerentes a cada híbrido, já que o Hy Mark e o Orange Flesh são comercialmente "nobres", por isso recebem classificação comercial diferenciada (embalagem).

Observou-se interação entre poda e densidade de semeio para o número de frutos não-comercializáveis (Figura 2A), o qual, nas plantas submetidas à poda, aumentou com a densidade de semeio. Entretanto, nas plantas não podadas o número máximo de frutos nãocomercializáveis (6.243) ocorreu sob população de 38.090 plantas ha-1 $^{-1}$ Aumento no número de frutos nãocomercializáveis com aumento na densidade de semeio também foi verificado por Nogueira et al. (2001) e Chaves et al. (2001b), trabalhando com os mesmos híbridos, Orange Flesh e Hy Mark, e densidades de semeio semelhantes às deste trabalho, porém em locais diferentes. A causa desse aumento é atribuída a limitações dos recursos do solo, em es- tádio mais avançado do desenvolvimento, especialmente durante a frutificação, e à sobreposição das folhas, o que favorece a competição por luz.

O maior número de frutos de plantas podadas $(1,30)$ em relação às plantas não podadas $(0,93)$ pode ser atribuído ao maior número de ramificações estimuladas pela poda da gema apical e, conseqüentemente, maior número de gemas floríferas e pegamento dos frutos.

Observou-se diminuição do número de frutos por planta com o aumento da densidade de semeio em todos os híbridos (Figura 2B). O menor espaçamento disponível às plantas favorece maior competição por elementos do solo e luz, diminuindo com isso a atividade fotossintética, produção de ramos, folhas, frutos e aumentando o número de flores masculinas (Wien, 1997). Resultados semelhantes foram obtidos por Grangeiro et al. (1999a), em híbridos de melão amarelo Gold Mine, AF 646 e XPH 13096, com variações populacionais de 10 a 40 mil. Diminuição no número de frutos por planta, em melão, também foram encontrados por Knavel (1991), nas cultivares 'Main Dwarf', 'Mainstream' e 'Ky-P ${ }_{7}$ ' e por Maynard (1998), na cultivar 'Superstar'.

Houve interação significativa entre a poda e híbridos quanto à massa média de frutos, sendo que a poda proporcionou frutos de maior massa média nos dois híbridos (Tabela 1). Semelhantemente, Monteiro \& Mexia (1988) verificaram que a poda promo- veu o aumento da área foliar e, conseqüentemente, maior translocação de reservas para o fruto, resultando em maior massa média. Esses resultados divergem dos encontrados por Pedrosa et al. (1991), em melão cv. Valenciano Amarelo e por Maruyama et al. (2000), em híbridos de melão rendilhado Bônus $\mathrm{n}^{\circ}$ 2 e D. Carlos, em que a poda da haste principal não influenciou na massa média de frutos. A diferença entre os resultados pode estar relacionada aos diferentes materiais genéticos utilizados.

A redução na massa média dos frutos com o aumento da densidade de semeio (Figura 2C) pode ser devido à maior competição entre plantas por recursos do meio, como água, nutrientes e luz nas maiores densidades, sendo os mesmos insuficientes para manutenção da planta e incremento da massa média dos frutos. Mendlinger (1994), em melão tipo Gália e Grangeiro et al. (1999a) em melões amarelo, estudando variações populacionais semelhantes, observaram que à medida que aumentaram a densidade de semeio houve redução na massa média de frutos em todos os híbridos estudados, com valores de 18,85\% (melão Gália) e de 12,00 a $27,60 \%$ (melões amarelo). Reduções também foram observadas por Maynard (1998) e Gualberto et al. (1999). No entanto, Knavel (1991) observou que o espaçamento entre plantas de melão teve efeito mínimo na massa média dos frutos, verificando efeito significativo apenas para a cultivar 'Honey Bush'. Na 
tentativa de explicar essa tendência, maior densidade de semeio e menor massa média dos frutos, o autor verificou que a área foliar sombreada foi superior ao duplicar a população de plantas. Esse sombreamento indica menor quantidade de irradiância interceptada pelas plantas, ou seja, em estádios mais avançados de desenvolvimento essa sobreposição das folhas induz à redução da taxa fotossintética e, conseqüentemente, menor assimilação e distribuição dos fotoassimilados, não dispondo, portanto, de uma quantidade suficiente, necessária à manutenção da planta e crescimento do fruto.

Houve interação significativa entre poda e híbridos quanto à relação de formato, sendo que os dois híbridos submetidos à poda apresentaram formato oblongo (Tabela 1). A poda da haste principal promove o rápido crescimento das hastes laterais, em razão das auxinas e outros fitohormônios que causam translocação de fotoassimilados para as gemas secundárias, aumentando as dimensões dos frutos, ou seja, a relação entre o comprimento e a largura deles. Esses resultados estão em concordância com os encontrados por Pedrosa et al. (1991) em melão cv. Valenciano amarelo, sendo que as plantas cuja haste principal foi podada apresentaram frutos de formato ligeiramente alongado.

A relação de formato foi máxima $(1,09)$ para a população de 37.841 plantas ha-1. Esse comportamento pode ser atribuído ao estresse sofrido pelas plantas nas maiores densidades de semeio e pelo maior número de frutos por planta nas baixas densidades. Resultados semelhantes foram encontrados por Cantliffe \& Phatak (1975) em pepino, em que verificaram reduções na relação de formato tanto em altas como em baixas densidades de cultivo. Grangeiro et al. (1999b), em híbridos de melão amarelo Gold Mine, AF 646 e XPH 13096 e Chaves et al. (2001a), em híbridos de melão 'Orange Flesh' e 'Hy Mark', verificaram que houve tendência de os frutos tornarem-se com formato redondo, à medida que se aumentou a densidade de semeio.

Houve interação significativa entre poda e híbridos para sólidos solúveis totais, sendo que plantas podadas do
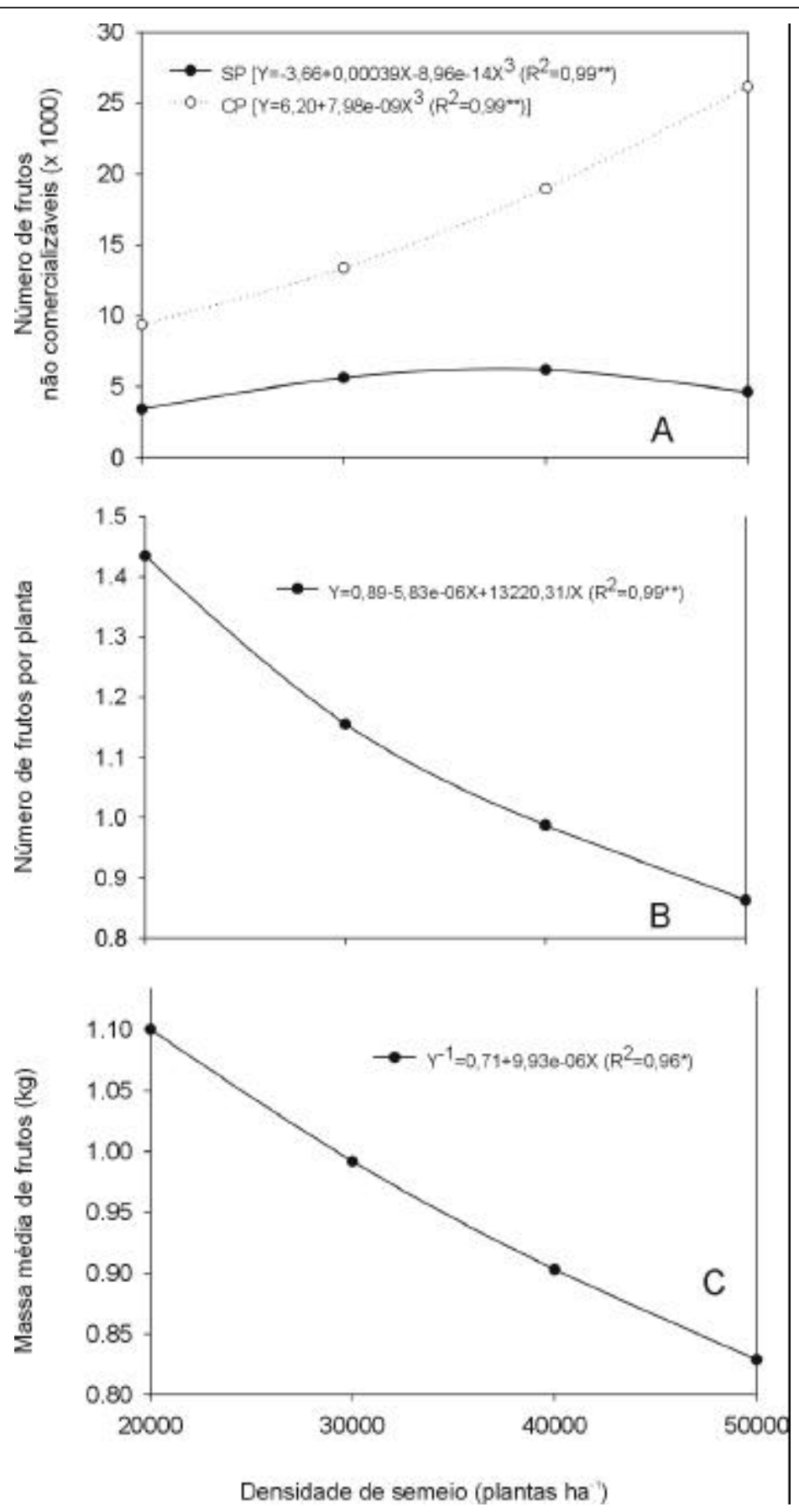

Figura 2. Número de frutos não-comerciáveis $(\mathrm{A})$ sem $(\mathrm{SC})$ e com poda $(\mathrm{CP})$, número de frutos por planta (B) e massa média de frutos (C) de melão em função das densidades de semeio. Mossoró-RN, ESAM, 1998.

híbrido Hy Mark tiveram maior teor de sólidos solúveis (Tabela 1). Esse tipo de comportamento pode ser atribuído à maior área foliar por fruto nas plantas podadas e com isso maior translocação de açúcares solúveis para o fruto. Quanto aos híbridos, a variação pode ser atribuída à natureza genética intrínseca de cada material. Monteiro \& Mexia (1988) verificaram que as plantas dos melões 'MacDimon' e 'Hawest king', podadas após a segunda folha, apresentaram área foliar e teor de sólidos solúveis dos frutos mais elevados que aquelas não podadas, indicando existir correlação positiva entre a área foliar e o teor de sóli- 
dos solúveis nos frutos. Maruyama et al. (2000) também verificaram interação significativa entre híbridos e sistema de condução com uma e duas hastes para sólidos solúveis, sendo que as plantas do híbrido 'D. Carlos', conduzidas com duas hastes, tiveram frutos com conteúdo de sólidos solúveis mais elevados, em relação às plantas conduzidas com uma haste.

O teor de sólidos solúveis totais não foi influenciado significativamente pelas densidades de semeio. Esse tipo de comportamento indica que o aumento no número de plantas por área, até a densidade máxima estudada, não influenciou a translocação de açúcares solúveis para o fruto, mesmo com o aumento na competição entre plantas por recursos do meio. Semelhantemente, Grangeiro et al. (1999b) não observaram efeito significativo da densidade de semeio (10; 20; 30 e 40 mil plantas ha$\left.{ }^{1}\right)$ para essa característica, quando trabalharam com melões tipo amarelo, com os híbridos Gold Mine, AF 646 e XPH 13096, nas condições de Mossoró-RN. Gusmão et al. (2001) também não encontraram efeitos significativos das densidades de cultivo, 2,77 e 4,76 plantas $\mathrm{m}^{-2}$, nos híbridos Bônus no 2, D. Carlos, Pacstart e Nero. No entanto, Mendlinger (1994) encontrou resultados divergentes em melão Gália, onde o aumento da densidade de cultivo (20, 40 e 80 mil) induziu redução significativa da percentagem de sólidos solúveis totais.

As plantas de melão submetidas à poda tiveram maior massa média dos frutos, maior número de frutos por planta e, conseqüentemente, maior rendimento por área. Essa é, portanto, considerada prática fitotécnica importante, apresentando resultados satisfatórios nos híbridos Orange Flesh e Hy Mark, pertencentes aos grupos Honey Dew e Cantaloupe, respectivamente.

$\mathrm{O}$ aumento da densidade de cultivo exerceu influência negativa, diminuindo a massa média dos frutos, o número de frutos por planta e, conseqüentemente, a produtividade.

\section{LITERATURA CITADA}

BRACY, R.P.; PARISH. R.L. Row number, not plant spacing, affects melon production. Loisiana Agriculture, v. 37, n. 4, p. 29, 1994.

CANTLIFFE, D.J.; PHATAK, S.C. Plant population studies with pickling cucumbers grown for once-over harvest. Journal American of the Society for Horticultural Science, v. 100, n. 5, p. 464-466, 1975.

CARNEIRO FILHO, J. Produção e qualidade de frutos de melão cantaloupe influenciadas pela poda e pelo tutoramento, em condições de estufa e campo. Viçosa, 2001. 102f. (Tese mestrado), UFV.

CHAVES, S.W.P.; NOGUEIRA, I.C.C.; NEGREIROS, M.Z.; BEZERRA NETO, F.; COELHO, J.K.S. Qualidade de híbridos de melão em diferentes densidades de plantio no município de Alto do Rodrigues-RN. Horticultura Brasileira, Brasília, v. 19, Suplemento CD-Rom, 2001a.

CHAVES, S.W.P.; NOGUEIRA, I.C.C.; NEGREIROS, M.Z.; BEZERRA NETO, F.; COELHO, J.K.S. Rendimento de híbridos de melão em diferentes densidades de plantio no município de Alto do Rodrigues-RN. Horticultura Brasileira, Brasília, v. 19, Suplemento CD-Rom, julho 2001b. DIAS, R.C.S. Cadeia produtiva do melão no Nordeste. In: CASTRO, A.M.G. Cadeias produtivas e sistemas naturais: prospecção tecnológica. SPIBrasília. 1998. p. 440-493.

DUSI, A.N. Melão para exportação: aspectos técnicos da produção. Brasília, DENACOOP, Publicações Técnicas 001/92, 1992. 38 p.

FILGUEIRAS, H.A.C.; MENEZES, J.B.; ALVES, R.E.; COSTA, F.V.; PEREIRA, L.S.E. GOMES JÚNIOR, J. Colheita e manuseio póscolheita. Melão pós-colheita, Embrapa Agroindústria Tropical (Fortaleza, CE). Brasília: Embrapa Comunicação para Transferência de Tecnologia, 2000, p. 23-41.

GRANGEIRO, L.C.; PEDROSA, J.F.; BEZERRA NETO, F.; NEGREIROS, M.Z. Rendimento de híbridos de melão amarelo em diferentes densidades de plantio. Horticultura Brasileira, Brasília, v. 17, n. 3, p. 200-206, 1999a.

GRANGEIRO, L.C.; PEDROSA, J.F.; BEZERRA NETO, F.; NEGREIROS, M.Z. Qualidade de híbridos de melão amarelo em diferentes densidades de plantio. Horticultura Brasileira, Brasília, v. 17, n. 2, p. 110-113, 1999 b.

GUALBERTO, R.; RESENDE, F.V.; LOSSASSO, P.H.L. Produção e qualidade do melão rendilhado em estufa, em função do espaçamento e sistema de condução. Horticultura Brasileira, Brasília, v. 17, n. 3, p. 291, 1999. GUSMÃO, S.A.L.; BRAZ, L.T.; BANZATTO, D.A.; GUSMÃO, M.T. A. Efeito da densidades de plantio e cobertura do solo com filme de polietileno na qualidade de híbridos de melão rendilhado, cultivados em casa de vegetação. Horticultura Brasileira, Brasília, v. 19, Suplemento CD-Rom, 2001.
JANDEL SCIENTIFIC User's Manual. Califórnia: Jandel Scientific, 1991. 280 p. KNAVEL, D.E. Productivity and growth of shortinternode muskmelon plants at various spacings or densities. Journal of the American Society for Horticultural Science, v. 116, p. 926-929, 1991.

LOPES, J.F. Melhoramento genético (chuchu, melancia, melão e pepino) In: Cucurbitáceas. Informe Agropecuário, Belo Horizonte, v. 8, n. 85, p. 61-65, 1982.

MARTINS, S.R.; PEIL, R.M.; SCHWENGBER, J.E.; ASSIS, F.N.; MENDEZ, M.E.G. Produção de melão em função de diferentes sistemas de condução de plantas em ambiente protegido. Horticultura Brasileira, Brasília, v. 16, n. 1, p. 24-30, 1998.

MARUYAMA, W.I.; BRAZ, L.T.; CECÍLIO FILHO, A.B. Condução de melão rendilhado sob cultivo protegido. Horticultura Brasileira, Brasília, v. 18, n. 3, 2000.

MAYNARD, E.T.; SCOTT, W.D. Plant spacings affects yield of 'Superstar' muskmelon. HortScience, v. 32, n. 1, p. 52-54, 1998.

MENDLINGER, S. Effect of increasing plant density and salinity on yield and fruit quality in muskmelon. Scientia Horticulturae, v. 57, p. 4149, 1994.

MONTEIRO, A.A.; MEXIA, J.T. Influência da poda e do número de frutos por planta na qualidade dos frutos e produtividade do melão. Horticultura Brasileira, Brasília, v. 6, n. 1, p. 912, 1988.

NOGUEIRA, I.C.C.; PEDROSA, J.F.; SANTOS JÚNIOR, J.J.; VALE, M.F.S.; ANDRADE, F.V. Produção de híbridos de melão submetidos à poda e diferentes densidades de plantio. Horticultura Brasileira, Brasília, v. 19, Suplemento CD-Rom, 2001.

PAIVA, W.O.; SABRY NETO, H.; LOPES, A.G.S. Avaliação de linhagens de melão. Horticultura Brasileira, Brasília, v. 18, n. 2, p. 109-113, 2000. PEDROSA, J.F. Cultura do Melão. Mossoró: ESAM, 1997. 50 p.

PEDROSA, J.F.; TORRES FILHO, J.; MEDEIROS, I.B. Poda e densidade de plantio em melão. Horticultura Brasileira, Brasília, v. 9, n. 1, p. 18-20, 1991.

PIMENTEL, C.R.M.; ALVES, R.E.; FILGUEIRAS, H.A.C. Mercado internacional: situação atual e perspectivas. Melão pós-colheita, Embrapa Agroindústria Tropical (Fortaleza, CE). Brasília: Embrapa Comunicação para Transferência de Tecnologia, 2000, p. 9-12. RIBEIRO JÚNIOR, I.R. Análises estatísticas no SAEG. Viçosa: UFV, 2001. 301 p. il.

WIEN, H.C. The cucurbits: cucumber, melon, squash and pumpkin. In: WIEN, H.C. et al. The physiology of vegetable crops. New York: CAB International, 1997. $662 \mathrm{p}$. 